\title{
Operative Procedures in the Elderly in Low-Resource Settings: A Review of Médecins Sans Frontières Facilities
}

\author{
Evan G. Wong • Miguel Trelles $\cdot$ Lynette Dominguez • \\ Jerome Mupenda Mwania $\cdot$ Cheride Kasonga Tshibangu • \\ Sanaul Haq Saqeb · Khalil U. R. Hazrati • \\ Shailvi Gupta $\cdot$ Gilbert Burnham $\cdot$ Adam L. Kushner
}

Published online: 2 December 2014

(C) Société Internationale de Chirurgie 2014

\begin{abstract}
Background As the demographic transition occurs across developing countries, an increasing number of elderly individuals are affected by disasters and conflicts. This study aimed to evaluate the elderly population that underwent an operative procedure at MSF facilities.

Methods A retrospective review of prospectively collected operative cases performed at MSF-Operational Centre Brussels (MSF-OCB) facilities between June 2008 and December 2012 was completed. Baseline demographic data, American Society of Anesthesiologists (ASA) physical status and surgical indications were collected for each patient. For each procedure, the degree of urgency, anesthesia type, and intra-operative mortality were noted. All patients aged 50 and over at the time of the procedure were considered elderly, as proposed by the World Health Organization (WHO). Comparisons were made with the 18-49 age group in order to elucidate differences between older and younger individuals. Results We reviewed a total of 93,385 procedures performed on 83,911 patients in 21 different countries. Patients aged 50 and over comprised $11.5 \%(9,628 / 83,911)$ of all patients. While most procedures $(57.6 \%)$ in the comparison group were urgent, this proportion decreased substantially in the elderly. Intra-operative mortality was considerably lower in the 50-59 group $(0.12 \%)$ but increased with each age stratum. The most commonly performed surgical procedures in the elderly included herniorrhaphies, simple and extensive wound debridements, abscess incision and drainages, minor tumorectomies, and urological procedures.

Conclusions In light of the increasing elderly population in developing countries, efforts should be made to better quantify and address their surgical needs.
\end{abstract}

\section{E. G. Wong $(\bowtie)$}

Centre for Global Surgery, McGill University Health Centre, 1650 Cedar Avenue, L9 411, Montreal, QC H3G 1A4, Canada e-mail: evwong@jhsph.edu

E. G. Wong · S. Gupta - G. Burnham - A. L. Kushner Department of International Health, Johns Hopkins Bloomberg School of Public Health, Baltimore, MD, USA

E. G. Wong · S. Gupta - A. L. Kushner

Surgeons OverSeas (SOS), New York, NY, USA

M. Trelles · L. Dominguez · J. Mupenda Mwania . C. Kasonga Tshibangu $\cdot$ S. Haq Saqeb $\cdot$ K. U. R. Hazrati Surgery, Anesthesia, Gynecology, and Emergency Medicine Unit, Médecins Sans Frontières, Brussels, Belgium

\author{
J. Mupenda Mwania \\ Referral General Hospital of Lubutu, Lubutu, \\ Maniema Province, Democratic Republic of the Congo \\ C. Kasonga Tshibangu \\ Referral General Hospital of Niangara, Niangara City, \\ Oriental Province, Democratic Republic of the Congo \\ S. Haq Saqeb \\ Ahmad Shah Baba General Hospital, Kabul, Afghanistan \\ K. U. R. Hazrati \\ Boost General Hospital, Lashkar-Gah, Afghanistan
}




\section{Introduction}

By 2050, it is estimated that over 2 billion people will be over 60 years of age worldwide [1] with $80 \%$ of them living in low- and middle-income countries (LMICs) [2]. Because the vast majority of humanitarian missions occur in LMICs [3, 4], in areas prone to conflict and natural disasters, this patient population is expected to be increasingly affected by emergency crises.

However, there is growing evidence that the specific needs of the aging population are not being addressed in humanitarian settings. For example, in a study led by HelpAge International, a non-governmental organization (NGO) dedicated to the care of the elderly, only $0.9 \%$ of projects included planned interventions specifically geared toward the elderly and less than $0.3 \%$ of funding was allocated to these projects [5].

Médecins Sans Frontières (MSF) is a humanitarian organization that provides medical and surgical assistance in conflict, disaster, and low-resource settings throughout the world based on need only, impartially and without discrimination [6]. Recognizing that the needs of the elderly may have been neglected, MSF reviewed their responses in Haiti and South Sudan to identify priority areas for action and research [7]. One key avenue was the collection of age-disaggregated data in order to guide resources for the elderly during humanitarian assistance missions.

Consequently, in an effort to help plan intervention efforts, this study aimed to evaluate the elderly population that underwent an operative procedure at MSF facilities.

\section{Materials and methods}

Institutional Review Board approval was obtained from the Johns Hopkins Bloomberg School of Public Health and from the MSF Ethical Review Board.

More detailed methods have previously been described [8]. Briefly, all cases performed at MSF-Operational Centre Brussels (MSF-OCB) facilities between June 2008 and December 2012 were reviewed. Procedures were recorded in a paper logbook that was transferred into an electronic archive every month. The head of the Surgical, Anesthesia,

S. Gupta

Department of Surgery, University of California San Francisco-

East Bay, Oakland, CA, USA

A. L. Kushner

Department of Surgery, Columbia University, New York, NY, USA
Gynecology, and Emergency Medicine unit in Brussels (MT) reviewed all data independently to ensure accuracy and completeness. Any discrepancies were immediately clarified with the data collecting personnel.

Baseline demographic data, American Society of Anesthesiologists (ASA) physical status and surgical indications were collected for each patient. For each procedure, the degree of urgency, anesthesia type, and intraoperative mortality were noted. Surgical indications and procedures were classified based on the standard MSF Operating Department Data Collection Guidelines that take into account the paucity of diagnostic tools [8].

Descriptive statistics were performed for our analysis. All patients aged 50 and over at the time of the procedure were considered elderly, as proposed by the World Health Organization (WHO) for the Minimum Data Set (MDS) on Aging project, albeit specifically for Africa [9]. Most developed countries define elderly based on the retirement age (i.e., 65). However, the lack of formal retirement programs in many LMICs renders this definition difficult to apply. Fifty years, as discussed during the WHO's 2001 Dar es Salaam MDS meeting, is more reflective of changes in physical capabilities and social roles in LMICs and takes into account lower life expectancies in these settings. For these reasons, 50 years was chosen to be more representative of social and cultural circumstances in LMICs. Analyses were stratified by decade, as pathologies were assumed to be heterogeneous amongst the elderly. Comparisons were made with the 18-49 age group in order to elucidate differences between older and younger individuals.

\section{Results}

We reviewed a total of 93,385 procedures performed on 83,911 patients in 21 different countries between June 2008 and December 2012. Patients aged 50 and over comprised $11.5 \%(9,628 / 83,911)$ of all patients. Of the total number of surgeries, $11.3 \%(10,511 / 93,385)$ were performed on an elderly patient. Patient demographics and procedure characteristics are displayed in Table 1.

The female to male ratio was lower in the elderly population. In contrast, there were more than 2 female patients for every male patient in the comparison group of ages 18-49 years.

Of note, $57.6 \%$ of procedures performed on patients aged 18-49 were considered urgent. In elderly patients, the proportion of urgent operations dropped considerably, consisting of only 19.0 to $22.6 \%$ of all operations performed. 
Table 1 Patient demographics and procedure characteristics divided by age group for all surgical procedures performed by MSF-OCB from 2008-2012

\begin{tabular}{llllll}
\hline Age (years) & Male:Female & ASA (SD) & Urgent (\%) & GA (\%) & $\begin{array}{l}\text { Intra-operative } \\
\text { mortality }(\%)\end{array}$ \\
\hline $18-49$ & $1: 2.09$ & $1.4(0.6)$ & $31,888(57.6)$ & $25,425(46.7)$ & $139(0.27)$ \\
$50-59$ & $1: 0.74$ & $1.6(0.6)$ & $952(21.1)$ & $2,116(47.3)$ & $5(0.12)$ \\
$60-69$ & $1: 0.50$ & $1.7(0.7)$ & $589(19.0)$ & $1,371(44.5)$ & $4(0.14)$ \\
$70-79$ & $1: 0.37$ & $1.7(0.7)$ & $300(19.2)$ & $645(41.3)$ & $4(0.21)$ \\
$80+$ & $1: 0.41$ & $1.9(0.8)$ & $101(22.6)$ & $217(48.7)$ & $1(0.24)$ \\
All ages & $1: 1.70$ & $1.5(0.7)$ & $33,830(52.1)$ & $29,774(46.5)$ & $152(0.25)$ \\
\hline
\end{tabular}

$M S F-O C B$ Médecins Sans Frontières Operational Centre Brussels, ASA American Society of Anesthesiologists' score, $S D$ Standard Deviation, GA General Anesthesia

Intra-operative mortality was highest in the 18-49 group, with a rate of $0.27 \%$. In the elderly population, this rate dropped to $0.12 \%$ in the $50-59$ group but doubled to $0.24 \%$ in the over 80 group.

Tables 2 and 3 show the most common procedures for each of the elderly age stratum compared to the 18-49 age range, separated by sex.

In the female comparison group, obstetrical indications predominated. In the 18-49 male group, the most common indications for surgical intervention were intestinal obstruction, bladder and kidney stones, symptomatic hernias, and trauma. The most common procedures in this age group were extensive and minor wound debridements and hernia repairs in males; and Cesarean sections and complex deliveries, including episiotomy repairs, in females.

In the elderly patients, both sexes were more comparable in terms of their surgical indications and procedures. Common surgical indications in the elderly included intestinal obstruction, bladder and kidney stones, symptomatic hernias, abscesses and trauma, specifically traffic and work-related accidents. These indications did not substantially differ across age strata, past age 50 .

The most commonly performed surgical procedures in the elderly included herniorrhaphies, simple and extensive wound debridements, abscess incision and drainages, minor tumorectomies, and urological procedures. Again, these did not differ considerably across elderly age groups.

\section{Discussion}

As the demographic transition occurs across LMICs in the near future, an increasing number of elderly individuals will fall victim to disasters and conflict. The importance of addressing the needs of this demographic will not be limited to sheer numbers, however. In many societies, the elderly are the pillars of the family structure and provide essential community and economic support. As migration, conflict, and AIDS attack these communities, the loss of parents increases the importance of the elderly in the care of young children [7].

Since disasters and conflict occur frequently in lowresource settings, where baseline surgical capacity has been documented to be tenuous [10,11], resource planning and allocation is of particular importance in this setting. It is thus logical to review the available data to plan future interventions, particularly for a patient population for which the needs have been inadequately met in the past. In fact, the high burden of surgical conditions has already been documented in the elderly of lower resource settings [12].

This constitutes, to our knowledge, the first review of surgical care of the elderly in the low-resource and humanitarian settings. This large study spanning 5 years and 21 countries provides valuable insight into the surgical procedures being performed for elderly patients in these settings. Data collection in these environments is challenging but as a global humanitarian medical organization in existence for over 40 years, MSF is in an ideal position to provide information on the needs of elderly patients needing surgical care.

This study first and foremost demonstrates the similarities and differences in the surgical needs of the elderly as opposed to younger adults. Obstetric procedures are less prominent in the elderly population. Hernia repairs and wound debridement maintain their importance across all age groups. Trauma is also ubiquitous across age groups, although gunshot wounds are prominent in younger adults, whereas traffic and work-related accidents are more important in the elderly. Minor tumor removal also gains importance in the elderly as opposed to the younger group.

Most interesting is the discrepancy in the proportion of emergency operations performed per age group. Due to altered physiological responses, decreased mobility, and 
Table 2 Three most common indications for interventions and most common surgical procedures performed per age category for male patients at MSF-OCB facilities between 2008 and 2012

\begin{tabular}{|c|c|c|c|}
\hline $\begin{array}{l}\text { Age category } \\
\text { (years) }\end{array}$ & & Common indications for males $(\%)$ & Common procedures for males $(\%)$ \\
\hline \multirow[t]{3}{*}{$18-49$} & 1 & $\begin{array}{l}\text { Intestinal obstruction, bladder and kidney stones, } \\
\text { hernia (23.8) }\end{array}$ & $\begin{array}{l}\text { Extensive debridement, fasciotomy, amputation of digits or } \\
\text { toes (19.9) }\end{array}$ \\
\hline & 2 & Gunshot wound (21.9) & Hernia repair, hemorrhoidectomy (17.9) \\
\hline & 3 & Traffic accident (15.9) & $\begin{array}{l}\text { Wound suturing or debridement, abscess incision and drainage } \\
\text { (17.6) }\end{array}$ \\
\hline \multirow[t]{3}{*}{$50-59$} & 1 & $\begin{array}{l}\text { Intestinal obstruction, bladder and kidney stones, } \\
\text { hernia }(48.2)\end{array}$ & Hernia repair, hemorrhoidectomy (39.8) \\
\hline & 2 & Abscess (11.1) & $\begin{array}{l}\text { Wound suturing or debridement, abscess incision and drainage } \\
\text { (12.7) }\end{array}$ \\
\hline & 3 & Traffic accident (10.6) & $\begin{array}{l}\text { Extensive debridement, fasciotomy, amputation of digits or } \\
\text { toes (11.0) }\end{array}$ \\
\hline \multirow[t]{3}{*}{$60-69$} & 1 & $\begin{array}{l}\text { Intestinal obstruction, bladder and kidney stones, } \\
\text { hernia (54.4) }\end{array}$ & Hernia repair, hemorrhoidectomy (44.1) \\
\hline & 2 & Abscess (11.8) & $\begin{array}{l}\text { Extensive debridement, fasciotomy, amputation of digits or } \\
\text { toes (10.1) }\end{array}$ \\
\hline & 3 & Disaster or work related (6.6) & $\begin{array}{l}\text { Wound suturing or debridement, abscess incision and drainage } \\
\text { (9.8) }\end{array}$ \\
\hline \multirow[t]{3}{*}{$70-79$} & 1 & $\begin{array}{l}\text { Intestinal obstruction, bladder and kidney stones, } \\
\text { hernia (57.2) }\end{array}$ & Hernia repair, hemorrhoidectomy (32.3) \\
\hline & 2 & Traffic accident (9.8) & $\begin{array}{l}\text { Extensive debridement, fasciotomy, amputation of digits or } \\
\text { toes (7.6) }\end{array}$ \\
\hline & 3 & Abscess (9.3) & Urological procedures (6.9) \\
\hline \multirow[t]{3}{*}{80 and over } & 1 & $\begin{array}{l}\text { Intestinal obstruction, bladder and kidney stones, } \\
\text { hernia (46.5) }\end{array}$ & Hernia repair, hemorrhoidectomy (32.6) \\
\hline & 2 & Abscess (13.6) & $\begin{array}{l}\text { Extensive debridement, fasciotomy, amputation of digits or } \\
\text { toes (13.3) }\end{array}$ \\
\hline & 3 & Disaster or work related (11.3) & $\begin{array}{l}\text { Wound suturing or debridement, abscess incision and drainage } \\
\text { (10.6) }\end{array}$ \\
\hline \multirow[t]{3}{*}{ Total } & 1 & $\begin{array}{l}\text { Intestinal obstruction, bladder and kidney stones, } \\
\text { hernia (30.8) }\end{array}$ & Hernia repair, hemorrhoidectomy (23.9) \\
\hline & 2 & Gunshot wound (17.9) & $\begin{array}{l}\text { Extensive debridement, fasciotomy, amputation of digits or } \\
\text { toes (17.6) }\end{array}$ \\
\hline & 3 & Traffic accident (14.1) & $\begin{array}{l}\text { Wound suturing or debridement, abscess incision and drainage } \\
\text { (15.9) }\end{array}$ \\
\hline
\end{tabular}

$M S F-O C B$ Médecins Sans Frontières Operational Centre Brussels

decreased support, the elderly often have delayed presentations to the hospital and are more likely to undergo urgent interventions $[13,14]$. In our study, however, the proportion of urgent surgical procedures performed in the elderly was less than half the proportion in the younger adults. This, along with the intra-operative mortality that does not significantly differ from the younger adults, leads us to hypothesize that the elderly requiring urgent surgical interventions may not arrive to the hospital in time due to limited pre-hospital transport and care. In fact, the overall intra-operative mortality rate is exceptionally low and outperforms even higher income settings. This is even more impressive in the context of conflict, disaster, and lower resource settings, and particularly in the care of elderly patients. It is possible that missed deaths may partially explain this finding; however, we believe that the low intra-operative mortality rate, in addition to the low proportion of emergent procedures, can be explained by an important selection bias. Important geographical, financial, and cultural barriers to surgical care exist, which are often disproportionately evident in elderly patients. Patients with multiple comorbidities, notably older individuals, are also less likely to survive until surgical care is available. Most deaths are therefore likely to occur at home or in the prehospital setting and are not captured in the intra-operative measures. Moreover, in the context of limited resources, organizations like MSF perform surgical procedures to maximize benefit at the population level; aggressive 
Table 3 Three most common indications for interventions and most common surgical procedures performed per age category for female patients at MSF-OCB facilities between 2008 and 2012

\begin{tabular}{|c|c|c|c|}
\hline $\begin{array}{l}\text { Age } \\
\text { category } \\
\text { (years) }\end{array}$ & & $\begin{array}{l}\text { Common indications for } \\
\text { females }(\%)\end{array}$ & $\begin{array}{l}\text { Common procedures for } \\
\text { females }(\%)\end{array}$ \\
\hline \multirow[t]{3}{*}{$18-49$} & 1 & Fetal-maternal (60.7) & Cesarean section (52.0) \\
\hline & 2 & $\begin{array}{l}\text { Endometritis, vesico- } \\
\text { vaginal fistula, uterine } \\
\text { perforation }(6.6)\end{array}$ & $\begin{array}{l}\text { Complex delivery, } \\
\text { episiotomy repair (6.3) }\end{array}$ \\
\hline & 3 & $\begin{array}{l}\text { Post-partum hemorrhage } \\
\text { (6.5) }\end{array}$ & $\begin{array}{l}\text { Wound suturing or } \\
\text { debridement, abscess } \\
\text { incision and drainage } \\
(5.6)\end{array}$ \\
\hline \multirow[t]{3}{*}{$50-59$} & 1 & $\begin{array}{l}\text { Intestinal obstruction, } \\
\text { bladder and kidney } \\
\text { stones, hernia (25.3) }\end{array}$ & $\begin{array}{l}\text { Hernia repair, } \\
\text { hemorrhoidectomy } \\
\text { (14.9) }\end{array}$ \\
\hline & 2 & Abscess (15.3) & $\begin{array}{l}\text { Removal of minor tumor } \\
\text { (13.1) }\end{array}$ \\
\hline & 3 & $\begin{array}{l}\text { Disaster or work related } \\
(9.2)\end{array}$ & $\begin{array}{l}\text { Wound suturing or } \\
\text { debridement, abscess } \\
\text { incision and drainage } \\
\text { (11.6) }\end{array}$ \\
\hline \multirow[t]{3}{*}{$60-69$} & 1 & $\begin{array}{l}\text { Intestinal obstruction, } \\
\text { bladder and kidney } \\
\text { stones, hernia (31.0) }\end{array}$ & $\begin{array}{l}\text { Hernia repair, } \\
\text { hemorrhoidectomy } \\
(17.8)\end{array}$ \\
\hline & 2 & Abscess (14.7) & $\begin{array}{l}\text { Removal of minor tumor } \\
\text { (12.0) }\end{array}$ \\
\hline & 3 & $\begin{array}{l}\text { Disaster or work related } \\
(10.4)\end{array}$ & $\begin{array}{l}\text { Extensive debridement, } \\
\text { fasciotomy, amputation } \\
\text { of digits or toes (10.8) }\end{array}$ \\
\hline \multirow[t]{3}{*}{$70-79$} & 1 & $\begin{array}{l}\text { Intestinal obstruction, } \\
\text { bladder and kidney } \\
\text { stones, hernia (25.9) }\end{array}$ & $\begin{array}{l}\text { Hernia repair, } \\
\text { hemorrhoidectomy } \\
(17.8)\end{array}$ \\
\hline & 2 & Abscess (23.0) & $\begin{array}{l}\text { Extensive debridement, } \\
\text { fasciotomy, amputation } \\
\text { of digits or toes (16.1) }\end{array}$ \\
\hline & 3 & $\begin{array}{l}\text { Disaster or work related } \\
\text { (14.4) }\end{array}$ & $\begin{array}{l}\text { Removal of minor tumor } \\
\text { (9.9) }\end{array}$ \\
\hline \multirow[t]{3}{*}{$\begin{array}{c}80 \text { and } \\
\text { over }\end{array}$} & 1 & $\begin{array}{l}\text { Disaster or work related } \\
(21.1)\end{array}$ & $\begin{array}{l}\text { Extensive debridement, } \\
\text { fasciotomy, amputation } \\
\text { of digits or toes (15.6) }\end{array}$ \\
\hline & 2 & Abscess (19.5) & Drain insertion (14.1) \\
\hline & 3 & Traffic accident (14.6) & $\begin{array}{l}\text { Wound suturing or } \\
\text { debridement, abscess } \\
\text { incision and drainage } \\
\text { (12.6) }\end{array}$ \\
\hline \multirow[t]{3}{*}{ Total } & 1 & Fetal-maternal (56.0) & Cesarean section (47.8) \\
\hline & 2 & $\begin{array}{l}\text { Intestinal obstruction, } \\
\text { bladder and kidney } \\
\text { stones, hernia }(8.1)\end{array}$ & $\begin{array}{l}\text { Wound suturing or } \\
\text { debridement, abscess } \\
\text { incision and drainage } \\
(6.0)\end{array}$ \\
\hline & 3 & $\begin{array}{l}\text { Endometritis, vesico- } \\
\text { vaginal fistula, uterine } \\
\text { perforation }(6.8)\end{array}$ & $\begin{array}{l}\text { Complex delivery, } \\
\text { episiotomy repair (6.0) }\end{array}$ \\
\hline
\end{tabular}

MSF-OCB Médecins Sans Frontières Operational Centre Brussels surgeries with a low probability of success and a high probability of death are not attempted. Furthermore, cases requiring competencies beyond what can be provided by the surgical team are not brought into the operating room; deaths from pathologies requiring subspecialized care that is not available would therefore not be counted as an intraoperative mortality. Specifically for the older population, other hypotheses to explain the low rates of urgent procedures and intra-operative mortalities include that surgical care may be perceived as futile in the elderly; their families therefore may not transport them to the hospital, or nonoperative management may be more likely to be chosen.

This study therefore has important implications for the care of the elderly in humanitarian response. When planning surgical capacity in disaster and conflict settings, we must take into account the growing number of elderly patients within the target population requiring care. This is particularly important, as we show that the operative needs of the elderly differ from younger individuals. In order to meet the needs of this population, skilled personnel, appropriate equipment, and sufficient supplies should be allocated according to the findings of this study. For example, resources for minor procedures such as herniorrhaphies, wound debridements, abscess incision and drainages, minor tumorectomies, and urological procedures should be prioritized rather than obstetrical procedures. Traffic and work-related prevention programs, as well as pre-hospital care initiatives, should also ensure to include the needs of the elderly. Moreover, as the number of elderly individuals grows in LMICs, the planning of any care in these settings will have to take into account the increasing prevalence of chronic diseases. Ultimately, as pre-hospital systems mature and surgical capacity improves, additional resources will be required to address the increased volume of patients with complex comorbidities surviving till surgical care.

This study has several limitations. Despite being a large review, it remains retrospective in nature and is limited to the scope of MSF-OCB's operations. The results of this study may therefore not be generalizable to other organizations. Moreover, since this study relies on hospital-based data, it is prone to selection bias as alluded to previously. Data validity always remains a concern, especially in conflict and disaster settings. Despite the implementation of data collection quality control mechanisms, including year-end reports addressing missed data, it is possible that certain procedures and deaths were undocumented. Another limitation is the classification system used for the database. Since this system was developed to respond specifically to MSF's operational needs, it does not provide specific diagnoses or procedures. Despite these limitations, 
this study still manages to highlight areas of importance.

To conclude, the surgical care of the elderly is often a neglected component of surgical research. To address the needs of aging populations, it is important to understand the types of conditions and procedures they normally receive. This study helps to highlight the surgical needs of elderly patients in conflict, disaster, and low-resource settings.

Acknowledgments The authors would like to thank all the MSF field teams operating in the countries included in this report for their patient care and their contributions to this study.

Conflict of interest No relevant conflicts of interest to declare.

\section{References}

1. World Health Organization (2008) The World Health Report. http://www.who.int/whr/2008/en/. Accessed 17 Oct 2013

2. World Health Organization (2012) Global brief for World Health Day. http://whqlibdoc.who.int/hq/2012/WHO_DCO_WHD_2012. 2_eng.pdf. Accessed 17 Oct 2013

3. Chu KM, Ford N, Trelles M (2010) Operative mortality in resource-limited settings: the experience of Medecins Sans Frontieres in 13 countries. Arch Surg 145:721-725

4. Nickerson JW, Chackungal S, Knowlton L et al (2012) Surgical care during humanitarian crises: a systematic review of published surgical caseload data from foreign medical teams. Prehosp Disaster Med 27:184-189

5. HelpAge International (2010) A study of humanitarian financing for older people. http://www.helpage.org/what-we-do/emergencies/ a-study-of-humanitarian-financing-for-older-people-and-peoplewith-disabilities/. Accessed 17 Oct 2013

6. Medecins Sans Frontieres (2013) About MSF. http://www.msf. org/about-msf. Accessed 17 Oct 2013

7. Medecins Sans Frontieres (2012) Older people in crises: a review of MSF's approach to vulnerability and needs. http://www.msf. org.uk/sites/uk/files/older_people_in_crisis_final_oct_2012.pdf. Accessed 17 Oct 2013

8. Wong EG, Trelles M, Dominguez L, et al. (2014) Surgical skills needed for humanitarian missions in resource-limited settings: common operative procedures performed at Medecins Sans Frontieres facilities. Surgery. In press.

9. World Health Organization (2013) Definition of an older or elderly person: Proposed Working Definition of an Older Person in Africa for the MDS Project. http://www.who.int/healthinfo/ survey/ageingdefnolder/en/. Accessed 12 Nov 2013

10. Weiser TG, Regenbogen SE, Thompson KD et al (2008) An estimation of the global volume of surgery: a modelling strategy based on available data. Lancet 372:139-144

11. Kushner AL, Cherian MN, Noel L et al (2010) Addressing the Millennium Development Goals from a surgical perspective: essential surgery and anesthesia in 8 low- and middle-income countries. Arch Surg 145:154-159

12. Wong EG, Kamara TB, Groen RS, et al. (2014) Prevalence of surgical conditions in individuals aged more than 50 years: a cluster-based household survey in Sierra Leone. World J Surg. doi: 10.1007/s00268-014-2620-1

13. Zenilman ME (1998) Surgery in the elderly. Curr Probl Surg 35:99-179

14. Karunakara U, Stevenson F (2012) Ending neglect of older people in the response to humanitarian emergencies. PLoS Med 9:e1001357 